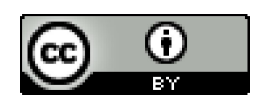

Esta obra está sob o direito de Licença Creative Commons Atribuição 4.0 Internacional.

\title{
O DESENV OLVIMENTO NAS ORGANIZAÇÕES PÚBLICAS E A QUALIDADE DE VIDA NO ÂMBITO TRABALHISTA
}

\author{
Maria Betânia Costa Góes ${ }^{1}$
}

\section{RESUMO}

O objetivo deste artigo foi mostrar que o fator qualidade de vida no trabalho deve estar presente em todas as organizações (públicas e privadas), pois, refletem nos aspectos comportamentais, ambientais e organizacionais, uma vez que devem ser significativas para a produtividade individual e coletiva, a competitividade e a qualidade das atividades desenvolvidas. Hipoteticamente falando a implantação da melhoria da qualidade de vida dos trabalhadores vem a contribuir para os aspectos orgânicos e psicológicos deles. Orgânicos, porque o ambiente de trabalho deve ser um local não estressante, isto é, distante de situações que causem ansiedade, angústia e até ambiente inadequado para desenvolver as atividades laborais. Psicológico, pelo fato de o ambiente ser harmonioso e adequado ao trabalho. Registra-se como sendo uma pesquisa bibliográfica e documental, a partir da catalogação de materiais coletados de revistas, livros e artigos publicados. Foi por intermédio destas fontes de estudo que se observou a necessidade da busca da qualidade de vida nas organizações, já que ajuda na construção de um ambiente harmonioso para o trabalho, sem estresse e adequado em suas relações pessoais.

Palavras-chave: Qualidade de Vida. Trabalho. Pessoas.

Submetido em dezembro de 2019 e aceito em janeiro de 2020.

\footnotetext{
${ }^{1}$ Possui graduação em Letras pela Universidade Federal de Alagoas.
} 


\section{INTRODUÇ̃̃O}

A visão da organização, considerada a partir da qualidade de vida no trabalho e da gestão, deixa transparecer a natureza da produtividade e do desenvolvimento das atividades, levando em consideração os aspectos físicos, ambientais e psicológicos.

Dentro dessa dinâmica, verifica-se que o mundo de trabalho passa por transformações e requer a qualificação dos profissionais das empresas. Igualmente, é necessário que surjam significativos investimentos (colaboradores e espaços físicos e materiais) para melhorar a qualidade do desempenho de suas atividades laborais.

Nessa arena reflexiva, percebe-se que em qualquer área laboral, as pessoas devem ter níveis significativos de qualidade e produtividade, ainda mais, precisam estar motivadas para participarem ativamente na execução de suas atividades e devidamente remuneradas.

$\mathrm{Na}$ verdade, tudo implica no desenvolvimento pessoal, tendo esta uma perspectiva crítica reflexiva, valorizando o pensar e o agir autônomos, integrando ao

\section{METODOLOGIA}

A pesquisa foi do tipo revisão de literatura tradicional, não sistemática, exploratória e descritiva, de natureza trabalho. Então, se há a gestão de pessoas, então há a qualidade de vida no ambiente de trabalho. Diante desta perspectiva traçou-se como objetivo identificar a contribuição da qualidade de vida para gestão de pessoas.

Para desenvolver esse artigo foi realizada a catalogação de livros, artigos publicados e revistas, levando em conta o estudo qualitativo e bibliográfico. Sendo o registro realizado, em conformidade com as normas de trabalho científico, levando em tela a catalogação dos materiais e posteriores registros das informações.

É um trabalho que se justifica por ter a qualidade de vida no trabalho como ponto fundamental para identificar os fatores que levam à desmotivação e compromete a gestão. Além do mais, grande parte dos trabalhadores estar suscetível às mudanças diárias de suas atividades, precisando se adaptar para obter a satisfação e desempenho de suas necessidades pessoais por intermédio do trabalho na organização. Diante deste contexto, este trabalho teve por objetivo discutir sobre o fator qualidade de vida no trabalho das organizações públicas e privadas.

qualitativa. Foram analisados artigos científicos publicados em periódicos nacionais, disponíveis nos formatos impresso e eletrônico, além de livros textos. 
Após análise dos trabalhos foi possível desenvolver cinco categorias temáticas: conceitos e técnicas para a melhoria na prestação dos serviços; indicadores de qualidade em serviços versus padrões de

\section{RESULTADOS E DISCUSSÕES}

O fator qualidade em atendimento ao cliente é imprescindível para uma ótima gestão nas organizações públicas. Esse detalhe básico gera a volta do cliente e ainda sim através do mesmo é realizada a propaganda boca a boca consequentemente trazendo novos clientes à empresa. Vejamos a seguir alguns tópicos que vem a esclarecer melhor este fator.

\section{Conceitos e técnicas para a melhoria na prestação dos serviços}

Da mesma forma que o objetivo de melhoria, o envolvimento das pessoas em todas as fases da prestação dos serviços é fundamental. Quanto mais preparados os funcionários para enfrentar problemas referentes à qualidade na prestação dos serviços, melhores níveis de produtividade serão obtidos.

O processo inicia-se com a identificação das necessidades e expectativas do cliente, manifestas nas dimensões do serviço. Com base nestas dimensões, a empresa pode identificar seus projetos críticos-chave e adequá-los às desempenho; elementos de Interação de um Serviço; qualidade nos serviços prestados; o desenvolvimento nas organizações e a qualidade de vida no trabalho.

necessidades dos seus clientes (LUDWIG, 2014).

Para uma melhoria do atendimento ao cliente na prestação dos serviços, é necessário estabelecer prioridades por meio dos processos que aumentam imediatamente a satisfação do cliente com o serviço prestado. A definição das prioridades no processo de melhoria consiste em identificar tarefas, procedimentos (atividades) ou sistemas, fundamentais para a qualidade dos serviços.

A seguir, são apresentadas ferramentas e técnicas que podem ser utilizadas para determinar as dimensões e requisitos dos serviços. Estas ferramentas ou técnicas de gestão da qualidade podem ser utilizadas na identificação das causas significativas de alguns efeitos não desejados. Entre estas técnicas para a melhoria da prestação de serviços, pode-se citar:

- Gestão da Qualidade Total (TQM);

- Os Círculos de Controle da Qualidade (CCQ);

- O Desdobramento da Função Qualidade (QFD); 
- O ciclo Plan-Do-Check-Act

(PDCA), Benchmarking e outros (LUDWIG, 2014).

Estas técnicas e ferramentas são úteis para analisar a melhoria do atendimento ao cliente durante a prestação de um serviço, visando a sua satisfação final.

\section{Indicadores de qualidade em serviços versus padrões de desempenho}

Digamos que uma pesquisa aponte que os clientes de um banco considerem como mais importantes duas das Dimensões da Qualidade em Serviços, referentes ao Fator Desempenho: (1) precisão (realizar exatamente o que se propõe) e (2) rapidez (no menor tempo possível). Os indicadores, neste caso, seriam: no primeiro "quantidade de erros" e no segundo "minutos". Os indicadores podem ser expressos em unidades numéricas - horas, metros, vezes - ou em alternativas de respostas -satisfeito, insatisfeito, bom, ruim - a perguntas sobre a opinião dos Clientes quanto a Qualidade percebida do Serviço nas suas diversas dimensões. (LOBOS, 2013)

Cada indicador de Qualidade deve ter um padrão de desempenho estabelecido. Por exemplo, como demonstra Lobos (2013): "uma oficina mecânica conclui que os clientes atribuem muita importância à
Dimensão 'eficácia'. Estabelece então, a ser medido, o requisito que denomina 'Sem Retorno'. O indicador, no caso, seria o 'número de retornos' e o padrão de desempenho igual à zero".

Em outro exemplo, um banco pode estar com problemas oriundos da demora na entrega de cartões magnéticos para os clientes. Estabelece como requisito à "mínima permanência dos cartões na agência antes de serem entregues aos clientes". O indicador seria a "quantidade de dias que os cartões permanecem na agência antes de serem entregues aos clientes" e o padrão de desempenho, estabelecido em conjunto com os executores do serviço, uma quantidade mínima possível de dias (LOBOS, 2013, p.76). É fundamental que o desempenho efetivo seja regularmente medido para comparações com os padrões de desempenho estabelecidos.

É também essencial não confundir indicadores de desempenho, que são expressões da Qualidade desejada, com metas de natureza gerencial ou orçamentária, que são objetivos de negócio. Preencher pelo menos 20 apólices de seguros por mês, sem cometer erros, evitando que os Clientes sejam prejudicados posteriormente, é um padrão de desempenho no âmbito da Qualidade em Serviços. Vender 20 apólices de seguros por 
mês, entretanto, é uma meta gerencial (LOBOS, 2013, p.78).

\section{Elementos de interação de um serviço}

As operações de serviços ocorrem em dois níveis que vão influenciar o relacionamento com o cliente: uma parte visível, chamada de jront office ou proscênio, local onde o cliente interage diretamente com o serviço (por exemplo, o salão de um restaurante), e back office ou retaguarda, onde tudo é preparado para o atendimento ao cliente (a cozinha desse restaurante).

Kotler (2014, p.69) afirma que para o cliente, o modo como a organização se estrutura internamente não está visível. Seu contato com a organização se faz por meio do ambiente físico e do relacionamento direto com o funcionário. Mas, para que esse ambiente e esse atendimento sejam os mais adequados, os serviços internos devem ser executados com foco no cliente, de modo que aqueles que lidam com ele diretamente possam prestar-lhe um serviço de alta qualidade.

No relacionamento pode haver maior ou menor contato pessoal e, respectivamente, menor ou maior uso de equipamentos. Pelo grau de utilização de equipamentos ou pessoas nos serviços é possível estabelecer algumas de suas muitas classificações (KOTLER, 2014).
Os serviços profissionais são aqueles em que as operações básicas ocorrem no jront office, o número de clientes atendidos num determinado período costuma ser reduzido e o profissional responsável por sua execução tem um alto grau de liberdade, podendo inclusive personalizar o atendimento.

Nesse tipo de serviço, as pessoas assumem maior importância e, consequentemente, a relação entre as atividades de marketing com destaque para o marketing interno e as de gestão de pessoas. Incluem-se nessa categoria os serviços prestados pelos profissionais liberais em geral (KOTLER 2014, p.70).

Por outro lado, os serviços de massa, como o próprio nome indica, atendem um grande número de pessoas num determinado período. Nesse caso, as operações importantes ocorrem no back room, com intensa utilização de equipamentos, havendo pouco contato direto e baixo índice de autonomia e personalização (KOTLER 2010, p.70).

$\mathrm{O}$ processo em si tem maior relevância. São exemplos de serviços de massa o transporte público, o cartão de crédito e a comunicação. As chamadas lojas de serviços como bancos, restaurantes e hotéis, por exemplo, é um meio-termo entre os serviços profissionais e os serviços de massa. 


\section{Qualidade nos serviços prestados}

Um melhor desempenho nos serviços gera vantagem competitiva, difícil de ser imitada pela concorrência, e é condição necessária para o retorno do cliente. Entretanto, uma razão para a busca da excelência nos serviços é que este não é suficiente para garantir diferenciação com relação aos concorrentes, nem para construir um relacionamento com os clientes, nem para competir em valor sem competir em preço, e nem para motivar o aprimoramento dos funcionários no trabalho.

Para obter estes benefícios, a qualidade é o nível de excelência que a empresa escolhe alcançar para satisfazer ao cliente. Então, se prestar serviços com qualidade é parte integrante da criação de valor, o próprio cliente deve constituir-se o foco da estratégia destes serviços.

Os serviços de qualidade sustentamse em princípios como: confiabilidade, surpresa, recuperação do serviço (fazer bem uma segunda vez) e integridade. "A obtenção e a manutenção de níveis aceitáveis de satisfação do consumidor, a respeito da qualidade dos serviços, são determinantes para o crescimento dos negócios e da qualidade, ao patamar de guia principal na implementação bem sucedida de programas gerenciais" (KOTLER, 2014, p.68).
A qualidade dos serviços está fundamentada na confiabilidade de realizar bem um serviço da primeira vez, na recuperação deste serviço fazendo bem da segunda vez, e num sólido serviço de interação, administrando as expectativas dos clientes (CARDOSO, 2012).

Segundo Juran (2013, p.54), “as características da qualidade dos serviços podem ser identificadas e agrupadas em atributos psicológicos, temporais, contratuais, éticos e tecnológicos. As mais importantes para os clientes de serviços são as psicológicas, éticas e temporais".

Para Berry e Parasuraman (2012, p.76), "os determinantes da qualidade do serviço, são: o acesso, a comunicação, a competência, a cortesia, a credibilidade, a confiança, a receptividade, a segurança, a tangibilidade e o conhecimento do cliente".

A qualidade de um serviço avaliada por um cliente é determinada pelo desempenho (razão de ser do negócio), atendimento (ato de prestação do serviço) e custo (associado ao valor para o cliente). Para todo serviço pode-se traçar um triângulo de interações entre os fatores do produto, do usuário e de pós-vendas.

Uma vez identificados os fatores que representam maior valor para seus clientes, o passo seguinte é planejar a qualidade do projeto e a conformidade.

As empresas de serviços, para aumentar sua criatividade, podem utilizar 
várias abordagens, como o nível de qualificação dos funcionários, a elevação da quantidade dos serviços sem detrimento da qualidade, a industrialização do serviço, acrescentando equipamentos $\mathrm{e}$ padronizando a prestação dos serviços, a obsolescência de serviços através da inovação do serviço ou do produto, o desenvolvimento de um serviço mais eficaz, o incentivo à realização de trabalhos que pertencem à empresa e o aproveitamento do poder de tecnologia (KOTLER, 2014).

Entre estas abordagens, a industrialização dos serviços leva a uma revisão dos conceitos sobre estes e sobre o tratamento dos recursos humanos utilizados na sua prestação.

Neste contexto, a industrialização dos serviços seria uma forma diferente de pensar seu conceito, incluindo aqueles ligados aos produtos, às vendas e às empresas. Para a industrialização dos serviços, é necessário considerar o cliente como quem compra os produtos pelos problemas que vão resolver. Assim, estes fazem parte de um produto, considerandose que as empresas de serviços fabricam produtos de forma eficiente e a preço baixo.

Neste sentido, a racionalidade, que é exercida efetivamente na fabricação, pode ser aplicada na prestação de serviços, proporcionando um aumento da produtividade. Eles podem ser industrializados através da tecnologia, colocando-se máquinas e equipamentos para uso das pessoas ou por meio da substituição de serviços pessoais por sistemas organizados e preparados antecipadamente; e por uma combinação de equipamentos com sistemas industriais planejados para manter a eficiência e a rapidez na prestação de serviços.

A industrialização dos serviços não significa a substituição de pessoas por máquinas. Sua orientação é para a obtenção de resultados através de formas novas de executar as tarefas atuais na prestação de serviços, ou de melhoria das mesmas (CARDOSO, 2012, p.29).

O conceito de que a solução para a melhoria dos serviços depende só das aptidões dos executores de tais serviços, impede que se possa realizar melhorias a nível de uso dos recursos humanos ou de formulação de novas tarefas ou processos, ou até mesmo de formas de organização.

É necessário mudar a concepção que diferencia o produto do serviço por uma abordagem total e organizacional, que faz da qualidade de serviços, como é percebida pelo cliente, uma força impulsionadora da operacionalização dos negócios. Todos devem considerar os serviços como o somatório de todos os valores entregues ao cliente, sejam eles tangíveis ou intangíveis (CARDOSO, 2012, p.30).

Para obter benefícios, um sistema de qualidade dos serviços deve também levar em conta os aspectos humanos envolvidos na prestação destes serviços, gerenciando os 
processos sociais nele envolvidos. Isto pode ser feito considerando-se as interações humanas como fator importante para a qualidade, reconhecendo a importância da percepção que o cliente tem da imagem, da cultura e do desempenho da empresa, além de desenvolver as habilidades do pessoal e motivá-lo para melhorar a qualidade e atender às necessidades do cliente (MOLLER, 2013).

\section{O desenvolvimento nas organizações e a qualidade de vida no trabalho}

A implantação da qualidade vida na organização privada ou pública precisa ser construída de forma positiva, especialmente, quando se valoriza o ambiente de trabalho e as relações humanas de seus empregados.

\footnotetext{
"A saúde e a qualidade do trabalho não podem ser negociadas como mais um mero elemento da produção. Tal abordagem visava superar a prevenção dos acidentes e doenças considerados diretamente ligados ao trabalho, priorizando a busca de outros nexos saúde-trabalho, para além da causalidade direta. Os agravos à saúde, que também ocorrem na população geral, quando relacionados ao trabalho assumem um perfil diferenciado." (LACAZ, 2013, p. 159).
}

Reforçando essa linha de pensamento, tem-se Fernandes e Machado (2018, p.2) que colocam que as empresas precisam estar atentas ao "tratamento em relação às pessoas, por estarem num meio de alta competitividade e modernização, tendo em vista que dependem extremamente delas para o alcance de seus objetivos e metas". Nesse momento, reforça-se a importância de um adequado ambiente de trabalho e com condições dignas para desenvolver qualquer atividade laboral.

\begin{abstract}
"O trabalho é forte elemento na construção da identidade humana que convive bem consigo mesmo, acredita em si e sente-se digno. As atividades que são de alguma forma impostas a um trabalhador que não consegue perceber sua finalidade ou destinação põem em risco sua sanidade mental. A natureza intrínseca das tarefas que as pessoas realizam atua como fonte exponencial de motivação no trabalho.” (ZANELLI, 2014, p.108).
\end{abstract}

Para compreender a importância da implantação de um modelo de QVT, faz-se necessário entender que as pessoas precisam trabalhar coletivamente para que alcancem "objetivos e metas da empresa, sem esquecer de seus objetivos individuais que cada vez se tornam mais precisos e necessários para uma vida saudável, necessitando assim que sejam consideradas parceiras da organização" (FERNANDES; MACHADO, 2018, p. 2).

Ao adentrar na compreensão como foram desenvolvidos nas organizações particulares em geral, foi preciso analisar os resultados dos estudos de Tolfo e Piccinini (2018, p. 4 - 6) que destacam "as melhores empresas para trabalhar no Brasil e a qualidade de vida no trabalho: disjunções entre a teoria e a prática". 
Pode-se averiguar que eles apontaram a qualidade de vida no trabalho, tendo como base os resultados divulgados pela revista Exame nos 1999, 2000 e 2001, levando em consideração os salários, benefícios, clima de trabalho estimulante, perspectivas de desenvolvimento na carreira, possibilidade de desenvolvimento e realização profissional.

Diante dos seus estudos, Tolfo e Piccinini (2013), podem registrar os seguintes itens que se tornaram significativos pelos empregados na ordem de importância das melhores empresas para trabalhar no Brasil:

Orgulho do trabalho e da empresa: relaciona-se com a relevância social da vida no trabalho, estando vinculado ao trabalho e à organização empregadora;

Clareza e a abertura na comunicação interna: vincula-se à liberdade de comunicação, levando em consideração que sugestões, críticas e conflitos sejam aproveitados pela organização para melhorar a qualidade dos seus produtos $\mathrm{e}$ serviços, aumentar a produtividade e atender adequadamente a clientela;

Oportunidade de carreira: relaciona-se a chance de crescimento e segurança com possibilidade de um tipo de carreira mais horizontalizada, em relação ao modelo hegemônico vigente até pouco tempo atrás;

Camaradagem no ambiente de trabalho: valoriza a atuação em times, em ambiente de trabalho agradável e descontraído, onde predomina a comunicação aberta;

Segurança e a confiança na gestão: refere-se à igualdade de oportunidades, relacionamento interpessoal e senso comunitário e sentimento de segurança no emprego, com o total comprometimento da gestão;

Iniciativas de treinamento $\mathrm{e}$ desenvolvimento: denomina-se de chance de crescimento e segurança profissional;

Inovação no sistema de trabalho: refere-se à importância de alguns processos que são chaves para compreender as pessoas no trabalho, como os seguintes: motivação, isto é, motivação intrínseca, significado do trabalho, foco no alcance de metas e pagamento por desempenho; aprendizagem, advinda da outra pessoa sobre os processos de trabalho e sobre as metas coletivas; e a mudança no processamento de informações e engajamento emocional; e

Os salários e benefícios: destaca-se por aparecerem como compensação justa e adequada, e compreende a renda apropriada ao trabalho, a equidade interna e a equidade externa. (TOLFO E PICCININI, 2013, p. 4).

Nessa senda, verifica-se que esses itens em ordem de importância decrescente, possibilitou a compreensão do que os empregados esperam das organizações. Mas, o que chamou a atenção em seus estudos foram os investimentos realizados pelas empresas que foram preferidas pelos empregados.

Registram Tolfo e Piccinini (2013, p. 4 - 6), como as principais vantagens associadas a cada uma das empresas pesquisadas que podem ser classificadas como sendo" Investimento: mantém destaque em qualificação; Pessoas: destacam-se como o centro do negócio; Programa de qualidade de vida: apresentase como sendo de ótima qualidade; e 
Ambiente de trabalho: registra-se como sendo um ambiente excelente.

Os desafios que surgem nas organizações concomitantemente no dia a dia das empresas podem ser trabalhados

\section{CONCLUSÃO}

A qualidade de vida no trabalho destaca-se como um assunto bastante discutido por alguns teóricos, como foi possível averiguar no transcorrer do trabalho, por isso não poderá ser desvinculado da qualidade dos ambientes e condições de trabalho, mas tudo dentro de um planejamento articulado entre os trabalhadores e gestores.

As Lesões por Esforço Repetitivo estão presentes na maioria das atividades profissionais desenvolvidas no mundo atual, podendo gerar uma série de prejuízos para a saúde dos funcionários e para as empresas com um todo. Cabe aos

\section{REFERÊNCIAS}

CARDOSO, O. R. Foco da qualidade total de serviços no conceito do produto ampliado. Florianópolis. Tese (Doutorado) - Departamento de Engenharia de Produção e Sistemas, Universidade Federal de Santa Catarina, Confederação Nacional da Indústria (Brasil), Banco Nacional do Desenvolvimento Econômico e Social (Brasil),2012.

FERNANDES, M. S.; MACHADO, M. M. A importância da qualidade de vida no trabalho no paço municipal de Gaspar. pela QVT, visto que se trata de um instrumento adequado para dar respostas às dificuldades do ambiente empresarial tendo assim um papel estratégico.

programas de qualidade de vida do trabalhador elaborados pelas organizações minimizar as incidências.

Outro ponto a registrar é que na construção de programa de qualidade de vida no dia a dia de trabalho tem que estar em foco o indivíduo como um todo (social). Não deve ser algo padronizado para atender tão somente o interesse da organização pública. Diante do exposto, percebe-se que as boas condições de trabalho precisam estar alicerçadas na participação dos colaboradores na organização e nas tomadas de decisões no processo de produção.

Revista Interdisciplinar Cientifica Aplicada, v. 1, n. 2, p. 1 - 20, 2007.

JURAN, J. M.; GRYNA, F. M. Controle da Qualidade Handbook. 4. ed. v. 3. São Paulo: Makron, McGrawHill, 2013

KOTLER, P. Administração de marketing: análise, planejamento, implementação e controle. 5. ed. São Paulo: Atlas, 2014.

LACAZ, F. A. C. Qualidade de vida no trabalho e saúdeldoença. Ciência saúde coletiva. vol.5, $\mathrm{n}^{\circ} 1$, Rio de Janeiro, 2013 
LOBOS, J. Encantando o cliente externo e interno. 9. Ed. revisada, São Paulo: J. Lobos, 2013.

\section{LUDWIG, A. Customer Relationship} Management-CRM. Disponível no site: www.fearp.usp.br/egna/resumos/ludwig.pd f. 2014 Acesso realizado em julho de 2019.

PARASURAMANA, A.; BERRY, L. L.; ZEITHAM, L. V. A. SERVQUAL: a multipleitem scale for measuring consumer perceptions of service quality. Journal of Retailing, v. 64, n. 1, 1988.
TOLFO, S. R.; PICCININI, V. C. As Melhores Empresas para Trabalhar no Brasil e a Qualidade de Vida no Trabalho: Disjunções entre a Teoria e a Prática, Revista de Administração Contemporânea, v. 05, n. 1, jan/abr, p. $165-193,2013$.

ZANELLI, J. Cs. Interação Humana e Gestão: a construção psicossocial de trabalho. São Paulo: Casa do Psicólogo, 2014. 